\title{
Risk factors for radiation-induced dental caries in patients with head and neck cancer
}

\author{
Sakiko Soutome ${ }^{*}$, Madoka Funahara ${ }^{2}$, Saki Hayashida ${ }^{2}$, Kazutaka Nakamura ${ }^{3}$ and Masahiro Umeda ${ }^{2}$ \\ ${ }^{1}$ Perioperative Oral Management Center, Nagasaki University Hospital, Japan \\ ${ }^{2}$ Department of Clinical Oral Oncology, Nagasaki University Graduate School of Biomedical Sciences, Japan \\ ${ }^{3}$ Student of Nagasaki University School of Dentistry, Japan
}

\begin{abstract}
Purpose: One of the major causes of osteoradionecrosis of the jaw in patients with head and neck cancer is thought to be progressive dental caries after radiotherapy (RT). The purpose of this study was to investigate associations between various clinical factors and dental caries after RT in order to establish prevention methods for radiation-induced progressive caries.
\end{abstract}

Materials and methods: Thirty-one patients with head and neck cancer who had undergone RT (RT group) and 25 patients who had undergone surgery alone (control group) were examined for dental caries at 1 or 2 years after RT. Various clinical factors were investigated with regard to their relationship with dental caries, via one-way analysis of variance followed by multiple regression analysis.

Results: Dental caries were increased in both groups, and the increase was significantly higher in the RT group than in the control group. When the radiation field included salivary glands and teeth, the number of dental caries was significantly higher as determined via univariate analysis. In the multivariate analysis, only the number of teeth in the radiation field was significantly correlated with the increase in dental caries.

Conclusion: The incidence of dental caries increases significantly after RT in patients with head and neck cancer. The major causes of progressive dental caries after RT seem to be direct damage to the tooth by the RT and reduced salivary flow due to the destructive effect of RT on the salivary gland.

\section{Introduction}

Radiotherapy (RT) is commonly performed in patients with head and neck cancer, but it can have various acute and late adverse effects, including oral mucositis, xerostomia, tasting disturbance, leukocytopenia, dermatitis, and osteoradionecrosis (ORN). Of these, ORN of the jaws is a serious late complication which markedly reduces the quality of life of patients [1]. Kojima et al. [2] recently reported that in a multicenter retrospective study 30 of 392 patients with head and neck cancer who underwent RT developed ORN. They also reported that periapical periodontitis before RT and tooth extraction after RT were risk factors for ORN, as were progressive dental caries that occurred after RT and progressed rapidly resulting periapical periodontitis, carious stump, or tooth extraction within a short period of time, They concluded that strict management of dental caries after RT was especially important for the prevention of ORN.

It is well known that dental caries often occurs after RT [3]. However, the cause of radiation-induced dental caries remains controversial. Many authors have suggested that a major cause of dental caries after RT is reduced self-cleaning in the oral cavity due to the abolition of salivary gland function by the RT, followed by xerostomia [3]. In contrast, Springer et al. [4] reported that direct damage to the tooth by RT increased caries risk, although Kielbassa et al. [5] reported that there were no differences between standard dental caries and radiation-associated dental caries as determined via both microscopic examination and in vitro investigation.

The aims of the current study were to investigate the status of dental caries after RT in order to establish prevention methods for radiationinduced progressive caries and ORN.

\section{Materials and methods}

Thirty-one patients with head and neck cancer who underwent RT at Nagasaki University Hospital between 2008 and 2015 and had panoramic X-ray examinations before RT and at 1 or 2 years after RT were retrospectively enrolled in the study. Patients whose radiation field did not include jaws, edentulous patients, or those receiving a total RT dose of $50 \mathrm{~Gy}$ or less were excluded from the study. Where it was deemed necessary, the patients in the RT group had had teeth that were thought likely to become infected extracted before the administration of RT, and they received professional oral care from a dentist and dental hygienist once a week during the RT. As a control group, 25 patients with oral cancer who underwent surgery alone during the same period and received panoramic X-ray examinations before surgery and at 1 or 2 years after surgery were recruited.

The variables examined in patients who underwent RT were age, gender, primary site, total radiation dose, radiation field, oral hygiene, alveolar bone loss, radiation exposure to the parotid and submandibular glands, radiation exposure to the teeth, and number of dental caries before RT and at 1 or 2 years after RT. The variables examined in the control group were age, gender, number of teeth, and number of dental caries before surgery and at 1 or 2 years after surgery.

Correspondence to: Sakiko Soutome, Perioperative Oral Management Center Nagasaki University Hospital, 1-7-1 Sakamoto, Nagasaki, 852-8588, Japan; Tel: 81-95-819-7698; Fax: 81-95-819-7700; Email- sakiko@nagasaki-u.ac.jp

Key words: cancer, caries, osteoradionecrosis, radiotherapy, salivary gland

Received: May 25, 2017; Accepted: June 13, 2017; Published: June 15, 2017 
Statistical analyses were performed using SPSS software (version 24.0; Japan IBM Co., Tokyo, Japan). The differences between background factors in the two groups were analyzed via Fisher's exact test or the Mann-Whitney U-test, and increases in dental caries at 1 and 2 years after treatment in the two groups were compared via the MannWhitney T-test. The correlations between each variable and increases in caries were analyzed via one-way analysis of variance, followed by multiple regression analysis.

Ethics approval was obtained from the Institutional Review Board of Nagasaki University Hospital (No. 16122601).

\section{Results}

Demographic factors, numbers of teeth, and numbers of teeth with caries at the start of treatment are summarized in Table 1 . The mean age of the patients in each group did not differ significantly. The primary site in the RT group was the oral cavity in 16 patients, the parotid gland in 5 , the oropharynx in 4 , the hypopharynx in 4 , and the maxillary sinus in 2 . Neither the mean number of teeth nor the mean number of dental caries in the RT and control groups differed significantly before treatment.

The mean increases in the number of dental caries after RT treatment were 2.68 at 1 year and 4.91 at 2 years. These increases were significantly higher than those in the control group, which were 0.00 at 1 year and 0.61 at 2 years after surgery (Figure 1 ).

The relationships between each variable investigated and increases in the number of dental caries at each time-point in the RT group are shown in Table 2. When the radiation field included one or two parotid or submandibular glands the mean increase in the number of caries per year was 1.1, but when three or four were included it was $5.3(p=0.007)$. When the radiation field included 14 teeth or less the mean increase in caries was 1.3 , but when it included 15 teeth or more it was $5.8(p<0.001)$. However, in the multivariate analysis only the number of teeth in the radiation field was significantly correlated with the increase in dental caries $(p<0.001)$.

\section{Discussion}

While various measures including the introduction of intensitymodulated radiation therapy, spacers during RT, and dental evaluation

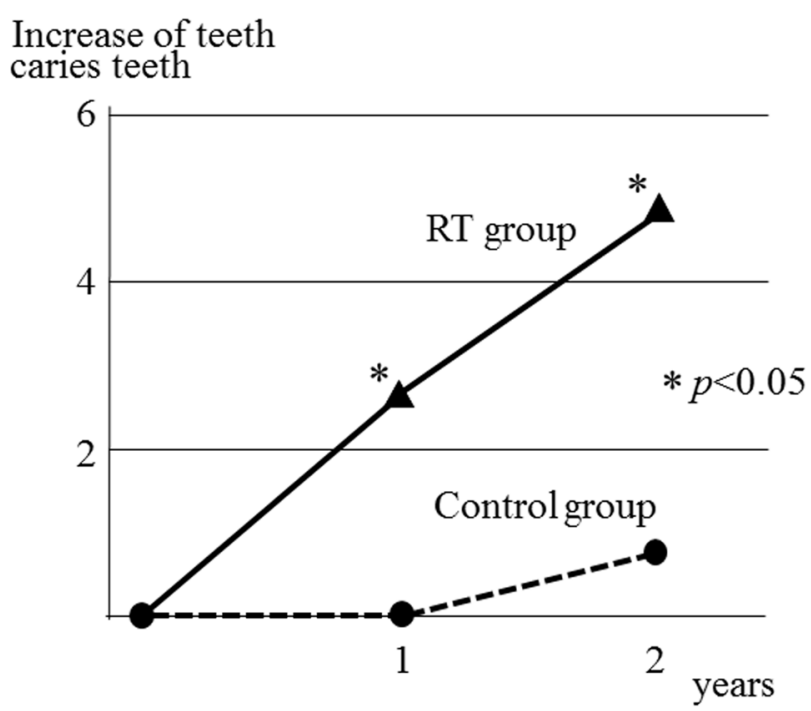

Figure 1. Increase in dental caries after treatment.
Table 1. Age, gender, primary site, and the numbers of teeth and caries of the patients in the two groups

\begin{tabular}{|c|c|c|c|c|}
\hline Factor & RT group $(n$ & $\begin{array}{c}\text { Control group }(n \\
=31)\end{array}$ & $p$ value \\
\hline Age & mean \pm SD & $62.3 \pm 13.0$ & $70.3 \pm 10.2$ & \\
\hline Gender & male & 22 & 13 & 0.051 \\
\hline & female & 9 & 12 & 0.173 \\
\hline Primary site & oral cavity & 16 & 25 & \\
\hline & parotid gland & 5 & 0 & \\
\hline & oropharynx & 4 & 0 & \\
\hline & hypopharynx & 4 & 0 & \\
\hline & maxillary sinus & 2 & 0 & 0.194 \\
\hline Number of teeth & mean \pm SD & $21.3 \pm 6.8$ & $19.0 \pm 5.7$ & 0.589 \\
\hline $\begin{array}{c}\text { Number of } \\
\text { caries }\end{array}$ & mean \pm SD & $1.0 \pm 1.4$ & $1.0 \pm 1.8$ & \\
\hline
\end{tabular}

Table 2. Risk factors for multiple caries

\begin{tabular}{|c|c|c|c|c|c|}
\hline Factor & Category & Cases & $\begin{array}{c}\text { Increase in } \\
\text { caries per } \\
\text { year }\end{array}$ & $\begin{array}{c}p \text { value } \\
\text { (univariate) }\end{array}$ & $\begin{array}{c}p \text { value } \\
\text { (multivariate) }\end{array}$ \\
\hline \multirow{2}{*}{ Age } & $<65$ years & 15 & 3.3 & 0.200 & 0.811 \\
\hline & $\geq 65$ years & 16 & 1.9 & & \\
\hline \multirow{2}{*}{ Gender } & male & 22 & 3.3 & 0.166 & 0.194 \\
\hline & female & 9 & 0.8 & & \\
\hline \multirow[t]{2}{*}{ Primary site } & $\begin{array}{c}\text { oral/ } \\
\text { oropharynx }\end{array}$ & 20 & 3.2 & 0.476 & 0.274 \\
\hline & others & 11 & 1.4 & & \\
\hline \multirow{2}{*}{ Oral hygiene } & good & 29 & 2.2 & 0.110 & 0.065 \\
\hline & poor & 2 & 7.0 & & \\
\hline \multirow{2}{*}{$\begin{array}{l}\text { Alveolar } \\
\text { bone loss }\end{array}$} & $<1 / 2$ & 28 & 2.3 & 0.112 & 0.074 \\
\hline & $\geq 1 / 2$ & 3 & 5.3 & & \\
\hline \multirow{2}{*}{$\begin{array}{l}\text { Number of } \\
\text { submandibular } \\
\text { and parotid } \\
\text { glands in the } \\
\text { RT field }\end{array}$} & $1-2$ & 20 & 1.1 & $0.007 *$ & 0.155 \\
\hline & $3-4$ & 11 & 5.3 & & \\
\hline \multirow{2}{*}{$\begin{array}{l}\text { Number of } \\
\text { teeth }\end{array}$} & $<20$ & 10 & 1.9 & 0.479 & 0.840 \\
\hline & $\geq 20$ & 21 & 2.9 & & \\
\hline \multirow{2}{*}{$\begin{array}{l}\text { Number of } \\
\text { teeth in the } \\
\text { RT field }\end{array}$} & $<14$ & 20 & 1.3 & $<0.001^{*}$ & $<0.001^{*}$ \\
\hline & $\geq 14$ & 11 & 5.8 & & \\
\hline
\end{tabular}

before RT are now commonly utilized, ORN remains a serious late adverse event in patients with head and neck cancer who have undergone RT. In most cases, the trigger is dental infection or tooth extraction. Numerous oral conditions such as poor oral hygiene [6], dental caries [7], periodontal disease [8], denture ulcer before RT [6], and tooth extraction after RT $[6,9,10]$ have been implicated as risk factors for ORN (Table 3). The Clinical Practice Guidelines in Oncology [11] state that dental evaluation-and when necessary, tooth extraction-should be performed at least 2 weeks before the initiation of RT. However, it has not been clarified which teeth should be extracted before RT. Furthermore, Koga et al. [12] reported that tooth extraction after RT was not a risk factor for ORN, and Chang et al. [13] reported that pre-irradiation dental extraction did not reduce the risk of ORN. Thus, the extraction of teeth before RT remains controversial.

In contrast, some investigators have asserted that rather than dental findings before RT, those after RT are more important for the prevention of ORN. Katsura et al. [14] reported that pre-RT oral findings were not associated with ORN, but periodontal disease and poor oral hygiene after RT were risk factors for its subsequent development. Kobayashi et al. [15] reported that progressive dental caries after RT was a risk factor for ORN. Kojima et al. [2] recently conducted a large-scale, multicenter, retrospective study on ORN risk 


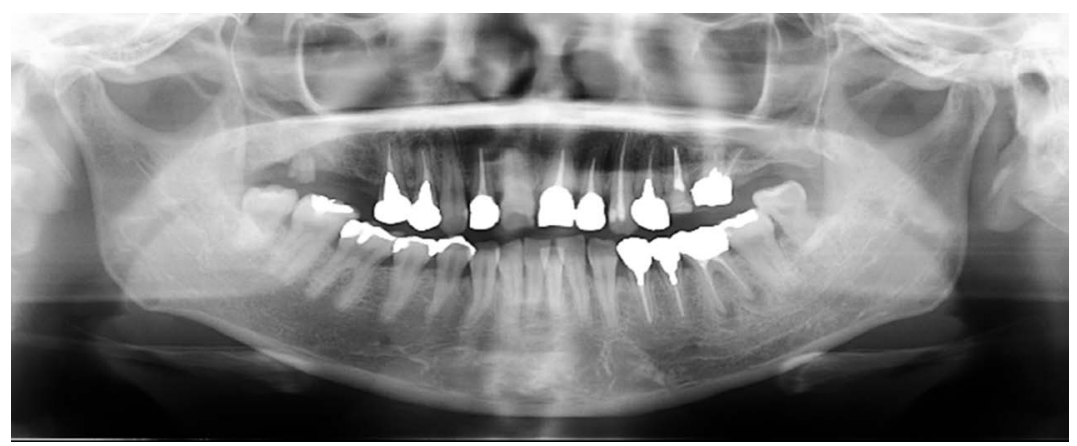

A

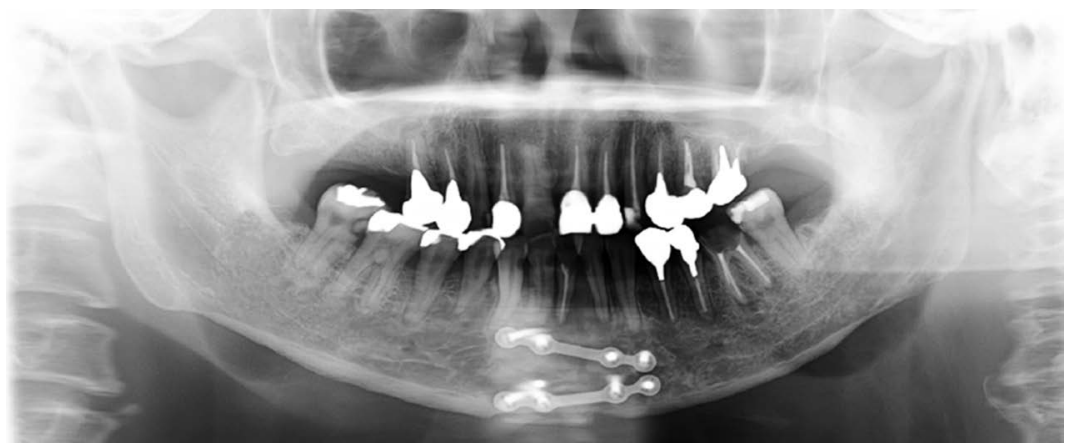

B

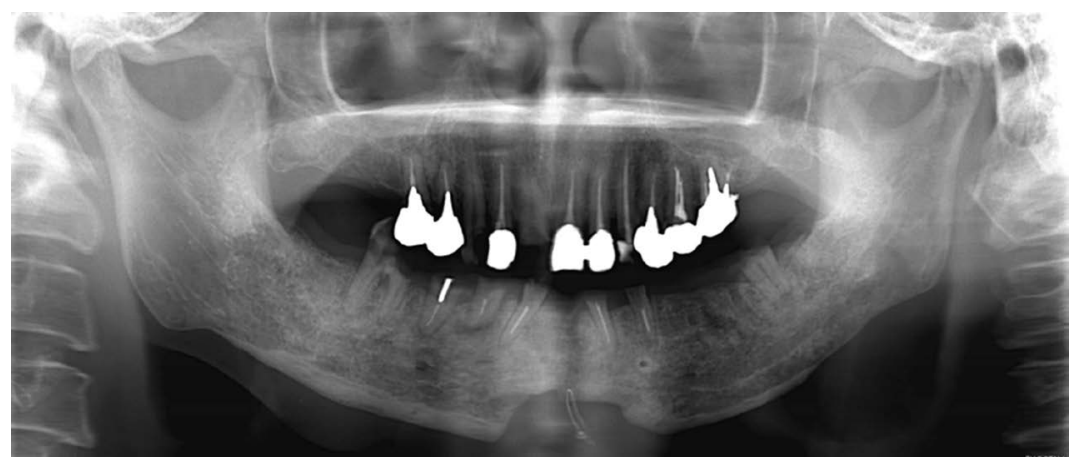

C

Figure 2. A 36-year-old female with tongue cancer who underwent postoperative chemo-radiotherapy. The radiation field included the lower jaw but not the upper jaw. Multiple dental caries occurred, mainly in the mandibular teeth. A: Panoramic X-ray before RT. B: Two years after RT. C: Six years after RT.

Table 3. Review of literature on ORN risk factors (dental status)

\begin{tabular}{|c|c|}
\hline \multicolumn{2}{|c|}{ Dental findings before RT } \\
\hline Reuther et al.[8] & periodontal disease before RT \\
\hline Niewaldet al.[7] & dental caries before RT \\
\hline Raguseet al.[6] & poor oral hygiene, denture ulcer before RT \\
\hline Kojima et al.[2] & periapical periodontitis before RT \\
\hline \multicolumn{2}{|c|}{ Dental findings after RT } \\
\hline Katsuraet al.[14] & $\begin{array}{c}\text { periodontal disease, poor oral hygiene } \\
\text { after RT }\end{array}$ \\
\hline Kobayashi et al.[15] & progressive caries after RT \\
\hline \multicolumn{2}{|c|}{ Tooth extraction } \\
\hline Morrishet al.[9] & tooth extraction after RT \\
\hline Thorn et al.[10] & tooth extraction after RT \\
\hline Raguseet al.[6] & tooth extraction after RT \\
\hline Kojima et al.[2] & tooth extraction after RT \\
\hline \multicolumn{2}{|c|}{ Others } \\
\hline Chang et al.[13] & $\begin{array}{c}\text { pre-RT tooth extraction does not reduce } \\
\text { ORN risk }\end{array}$ \\
\hline Koga et al. $[12]$ & $\begin{array}{c}\text { tooth extraction after RT is not a risk factor } \\
\text { for ORN }\end{array}$ \\
\hline
\end{tabular}

factors, and reported that periapical periodontitis before RT and tooth extraction after RT were both associated with the development of the condition. They also reported that the most common trigger of ORN was progressive dental caries that occurred after RT and progressed rapidly, resulting periapical periodontitis, carious stump, or tooth extraction. They recommended that in order to prevent ORN, it was advisable to extract mandibular molars with periapical periodontitis and perform strict caries management after RT.

Dental caries often occurs after RT, and the Clinical Practice Guidelines in Oncology [11] recommend topical fluoride application after RT. Radiation-induced dental caries are thought to be a result of reduced salivary flow as well as possible direct radiogenic damage [3], although the exact nature of the latter remains to be elucidated. Springer et al. [4] reported that direct and instant radiogenic damage of pulpal tissue collagen could be demonstrated. In the current study, univariate analysis showed that both RT involving the salivary glands and that involving the teeth were risk factors for multiple dental caries, and in multivariate analysis RT involving the teeth was a significant independent risk factor for multiple caries. Sometimes multiple dental 
caries occur only in the irradiated region (Figure 2A, 2B, 2C), indicating direct damage to the tooth by RT rather than reduced salivary flow. These findings suggest the importance of strengthening teeth, as well as the promotion of salivary secretion, to prevent progressive caries after $\mathrm{RT}$. We are now initiating an interventional study on the prevention of dental caries after RT via topical fluoride application using the tray method.

\section{Acknowledgments}

We would like to thank Editage (www.editage.jp) for English language editing.

\section{References}

1. Marx RE (1983) Osteoradionecrosis: a new concept of its pathophysiology. J Ora Maxillofac Surg 41: 283-288. [Crossref]

2. Kojina Y, Yanamoto S, Umeda M, Kawashita Y, Saito I, et al. (2017) Relationship between dental status and development of osteoradionecrosis of the jaw: A multicenter retrospective study. Oral Surg Oral Med Oral Pathol Oral Radiol Endod, in press.

3. Gupta N, Pal M, Rawat S, Grewal MS, Garg H, et al. (2015) Radiation-induced dental caries, prevention and treatment - A systematic review. Natl J Maxillofac Surg 6: 160166. [Crossref]

4. Springer IN, Niehoff P, Warnke PH, Böcek G, Kovács G, et al. (2005) Radiation caries-radiogenic destruction of dental collagen. Oral Oncol 41: 723-728. [Crossref]

5. Kielbassa AM, Hinkelbein W, Hellwig E, Meyer-Lückel H (2006) Radiation-related damage to dentition. Lancet Oncol 7: 326-335. [Crossref]

6. Raguse JD, Hossamo J, Tinhofer I, Hoffmeister B, Budach V, et al. (2016) Patient and treatment-related risk factors for osteoradionecrosis of the jaw in patients with head and neck cancer. Oral Surg Oral Med Oral Pathol Oral Radiol 121: 215-221. [Crossref]
7. Niewald M, Barbie O, Schnabel K, Engel M, Schedler M, et al. (1996) Risk factors and dose-effect relationship for osteoradionecrosis after hyperfractionated and conventionally fractionated radiotherapy for oral cancer. Brit J Radiol 69: 847851. [Crossref]

8. Reuther T, Schuster T, Mende U, Kübler A (2003) Osteoradionecrosis of the jaws as a side effect of radiotherapy of head and neck tumour patients--a report of a thirty year retrospective review. Int J Oral Maxillofac Surg 32: 289-295. [Crossref]

9. Morrish RB Jr, Chan E, Silverman S Jr, Meyer J, Fu KK, et al. (1981) Osteonecrosis in patients irradiated for head and neck carcinoma. Cancer 47: 1980-1983. [Crossref]

10. Thorn JJ, Hansen HS, Specht L, Bastholt L (2000) Osteoradionecrosis of the jaws: clinical characteristics and relation to the field of irradiation. J Oral Maxillofac Surg 58: 1088-1093. [Crossref]

11. National Comprehensive Cancer Network (2016) Clinical Practice Guidelines in Oncology. Head and Neck Cancers Version 1.

12. Koga DH, Salvajoli JV, Kowalski LP, Nishimoto IN, Alves FA (2008) Dental extractions related to head and neck radiotherapy: ten-year experience of a single institution. Oral Surg Oral Med Oral Pathol Oral Radiol Endod 105: e1-6. [Crossref]

13. Chang DT, Sandow PR, Morris CG, Hollander R, Scarborough L, et al. (2007) Do pre-irradiation dental extractions reduce the risk of osteoradionecrosis of the mandible? Head Neck 29: 528-536. [Crossref]

14. Katsura K, Sasai K, Sato K, Saito M, Hoshina H, et al. (2008) Relationship between oral health status and development of osteoradionecrosis of the mandible: a retrospective longitudinal study. Oral Surg Oral Med Oral Pathol Oral Radiol Endod 105: 731-738. [Crossref]

15. Kobayashi W, Teh BG, Kimura H, Kakehata S, Kawaguchi H, et al. (2015) Comparison of osteoradionecrosis of the jaw after superselective intra-arterial chemoradiotherapy versus conventional concurrent chemoradiotherapy of oral cancer. J Oral Maxillofac Surg 73: 994-1002. [Crossref]

Copyright: $\odot 2017$ Soutome S. This is an open-access article distributed under the terms of the Creative Commons Attribution License, which permits unrestricted use, distribution, and reproduction in any medium, provided the original author and source are credited. 